\title{
On Urgent Socioeconomic Measures During The Corona Crisis
}

\author{
V. K. Fal'tsman* \\ Institute of Applied Economic Research of the Russian Presidential Academy of National Economy and Public Administration, \\ Moscow, 119571 Russia \\ *e-mail:m975032@gmail.com \\ Received April 17, 2020; revised April 29, 2020; accepted May 5, 2020
}

\begin{abstract}
In anticipation of the impending crisis, the article considers two branches of anticrisis measures: 1) the creation of an economic structure that ensures the accelerated growth of small and medium-sized enterprises, the products of which can partially offset the loss of income from the export of hydrocarbons due to import substitution and export of manufacturing goods and services; 2) social protection of the poorest segments of the population from the possible increase in unemployment and poverty.
\end{abstract}

Keywords: corona crisis, anticrisis measures, small and medium-sized enterprises, social protection of the population

DOI: $10.1134 / \mathrm{S} 1075700720050056$

An emergency has occurred in the Russian economy [1-4]. In the past five years, the country has been close to zero growth. Competition in the hydrocarbon market is intensifying, and the most affordable oil reserves are poorer. In conditions of budgetary dependence on oil and natural gas, world prices for oil and natural gas are falling. Sanctions are constantly growing. Due to the complicated geopolitical situation, the Russian economy carries an increased external load. Dangerous competition with Chinese producers is intensifying. Due to depopulation, the number of people employed in the economy is declining. The cadres are getting old.

The Covid-19 pandemic added unprecedented unpredictability to the situation. The pandemic hit hard on business, especially passenger transportation, tourism, and catering. The magnitude of the impending destructive impact of the pandemic on the global and Russian economies has not yet been determined. But global oil demand has already fallen by $20 \%$.

We will arbitrarily denote the future crisis as a "corona crisis." Regardless of the timing and extent of the emerging economic crisis, a number of urgent stabilization measures are needed to contain its effects. Among the most important of them, in our opinion, is a deep institutional reform of the economy, aimed at creating a special economic structure for the accelerated development of small and medium-sized enterprises (SMEs). World experience shows that this is the first, if not the only, way out of the Russian economy from the zone of zero growth. For example, in the United States, $98 \%$ of the 29 million operating companies are SMEs. In Russia, the situation is different:
SMEs are under heavy pressure from the state administration, corruption, and large enterprises.

The development of production at SME enterprises should be aimed at compensating for possible losses from the reduction in sales of oil, natural gas and other traditional goods and services of the Russian economy. But in an emergency, most likely, it will not be possible to avoid a corona crisis. Therefore, the second part of the article discusses some areas of social support for the population from the threatening consequences of the crisis.

On the formation of a special economic structure for the accelerated development of SMEs. For the formation of a second economic structure of the Russian economy, it is not enough to limit oneself to traditional methods of supporting the development of SMEs, let alone their surface imitation. We need a deep institutional reform of the still weak sphere of SMEs [2]. The essence of the reform is to create conditions for the use of local entrepreneurial initiative, local resources and markets for the development of domestic goods production, import substitution and nonresource exports. To this end, the local entrepreneurial initiative must be exempted from the custody of the registering, licensing, inspection bodies, whose activities are sometimes associated with corruption.

SMEs are capable of producing a rich harvest of income and taxes in a short time. But you should not start harvesting when the cornfield has not yet ripened. Taxes (along with corruption and criminality) are the most dangerous enemy of SMEs, while they are not adequately protected by local and regional authorities. An ill-conceived fiscal policy can stifle weak sprouts of SMEs in the bud. For the success of 
the business, it may be advisable for a limited period to completely exempt new products from small enterprises from taxation. In any case, preferential taxation should be the primary measure of the upcoming reform of SME development.

The accelerated development of SMEs implies increased decentralization of economic development management. Responsibility for accelerated growth in the turnover of SMEs should be assigned to the regional and local administration, for which the main indicators of the quality of work should be indicators of the development of SMEs. Under this condition, the regional and local authorities will be forced to facilitate the access of SMEs to land, water, energy and transport infrastructure, and access to local markets without pretending to corrupt rents. The tax code and other regulatory documents should provide for the strengthening of the economies of regions and municipalities through the development of SMEs, a gradual reduction in centralized subsidies.

The formation of a second economic structure through institutional reform is exclusively constructive in nature, and can be aimed at strengthening the powerful vertically integrated system of large enterprises belonging to the first economic structure. With the support of the federal government, the regional entrepreneurial sector is able to complement and reinforce the powerful public sector, which forms the basis of the Russian economy and includes defense industry enterprises, the fuel and energy complex, transport, financial and other organizations. The economic structure of the SME sector not only does not suppress large state enterprises, but is also able to strengthen their economy.

For example, SMEs can help solve the complex problem of diversification of defense industry production into civilian products. But for this, the federal government should facilitate the joint activities of SMEs with defense industry enterprises, which is currently limited by the conditions of secrecy.

SME enterprises, somewhere on their own, and somewhere together with foreign companies, can help localize the production of cars by replacing the import of components and accessories, the scale of which in some years reaches 6-10 billion dollars.

Most Russian industries (except the extractive and financial sectors) have little chance of winning competition for international capital in global financial markets. As the corona crisis unfolds, capital outflows will increase. Therefore, after the successful strengthening of SMEs (but not earlier!), it can become an internal source of investment for large enterprises in the public sector.

Labor productivity in small enterprises is 1.7 times higher than in the national economy as a whole. However, small businesses, with the exception of startups, have limited opportunities for the development and production of innovative products. Moreover, the pre- dominant number of SMEs is concentrated in industries with a relatively low high technology output - in construction, agriculture, trade, and repair of household appliances.

The proportion of innovative products in small enterprises is half that of medium-sized enterprises, and five times less than in the national economy as a whole. However, the potential contribution of SMEs to the innovation process, we believe, is to expand the possibilities of implementing local creative initiatives and preserving domestic human capital from diversion abroad. The level of innovative activity and competitiveness of SMEs can be increased by creating and distributing state-owned enterprises leasing foreign equipment.

At the first stage of radical institutional reform, perhaps one should confine oneself to the accelerated growth of SMEs in the production of consumer goods including food, clothing, footwear and the necessary agricultural and chemical raw materials, as well as household appliances. These are areas with wide opportunities for import substitution and accelerated capital turnover. Promising areas for the development of SMEs are also individual housing construction, local tourism, and startups.

Financing the accelerated development of SMEs should be based mainly on the private capital of owners with moderate and limited loans from regional and municipal sources. It was this way that the development of Silicon Valley startups went. Loans at the federal level can pose a threat to SMEs: financial support from the state will inevitably be followed by inspections and strengthened government regulation, which is detrimental to private initiative.

Meanwhile, in the last years of the recession and the worsening economic situation, the autonomy ratio of small enterprises has halved: three quarters of their capital is borrowed. In these conditions, the threat of curtailing the activities of SMEs under the influence of the crisis is great. Therefore, to maintain the growth of the Russian economy, a deep institutional reform is needed that promotes the economic structure of the accelerated development of SMEs. In the economic life of Russia, this reform is called upon to play about the same role as the development of oil and gas production and export in the 1960-1970s.

Social protection of the population from the corona crisis. According to world ratings, Russia is not a poor country. In terms of GDP (PPP) per capita, the country is in 40th place in the world. But in terms of relative poverty, the country adjoins a group of countries with low rates. The reason for the discrepancy between income and poverty levels is a high income differentiation, which exceeds (by the ratio of extreme decile groups) 15 times. In the favorable period 2000-2010, the proportion of the population with incomes below the subsistence level decreased from 29.9 to $12.5 \%$. But in subsequent years of the recession, the propor- 
tion of the poor began to grow. Meanwhile, in the country there are 152 dollar millionaires [3].

In the years of the upcoming crisis, the challenge is to limit the spread of poverty, to prevent it from developing into a stage of poverty, when the state of the economy begins to adversely affect the health of the population and reduce the outlined increase in the active longevity of people.

In the context of the corona crisis, the most important measure of social support for the population from its consequences, in our opinion, is the redistribution of part of the income from the richest to the poorest. The prerequisites for such a redistribution of income have been formed over the past 20 years, when Russia's per capita GDP (PPP) grew by about three times. Accordingly, incomes and well-being of the wealthy segments of the population, their provision with equipment, real estate and other goods with the possibility of deferred demand increased.

Now the need has ripened for highly profitable groups of the population to introduce a progressive taxation scale adopted in many countries of the world. For the poorest segments of the population, taxes can be reduced, or, without canceling personal income tax, introduce targeted support for low-income families. In this latter case, support is financed by federal and regional budgets from funds from raising taxation of high incomes, and is implemented by local authorities, municipalities and prefectures.

In the second quarter in 2020, the proportion of the population with cash income below the subsistence level was $12.7 \%$. This is 18.6 million poor people. To bring the incomes of this poor group to a living wage, according to Rosstat estimates, they will need to add an additional amount equal to $1.3 \%$ of the total income of the population. In order to completely get rid of poverty, it will take only about 700 billion rubles. In anticipation of the impending crisis, Russia was one step away from the opportunity to get rid of poverty. True, from nominal poverty and calculated by the Russian method, different from European. How will the structure of income distribution change if, by introducing a progressive taxation scale, this amount is removed from high-income segments of the population and redistributed in favor of the least wealthy?

Rosstat shows the distribution of the total cash income of the population into five groups. In each group is equally $20 \%$ of the population, about 30 million people. But the volume of cash income by group is very different. If we take the total income as $100 \%$, then the fifth group with the highest incomes accounts for $47.1 \%$ of revenues, the next fourth group, $22.6 \%$, and the total for two highly profitable groups, $69.7 \%$ of income. If the amount equal to $1.3 \%$ of total income is withdrawn from these two groups through tax reform, then their share in the total amount of cash income will decrease slightly to $68.4 \%$. But at the same time, the share of the first group with the lowest incomes, which includes 18.6 million poor people, will increase from 5.3 to $6.6 \%$. From the introduction of a progressive taxation scale, affluent groups of the population will suffer slightly, and the most needy segments of the population will no longer be considered poor.

The progressive scale of taxation of the rich may prove to be an indispensable measure of social protection of the population from falling incomes during the corona crisis. The magnitude and duration of the crisis is currently unpredictable. Therefore, there is nothing left but an analysis of hypothetical assumptions.

Suppose the worst (according to modern estimates) scenario, when the level of per capita GDP (PPP) and, accordingly, population incomes will be reduced by a third. Then the size of the country's economy and standard of living will be reduced by the crisis to the level of about ten years ago, in 2007-2009. If the resulting losses are evenly distributed among all population groups, poverty will inevitably spread, and for the poorest segments of the population it will grow into poverty.

Therefore, for the first three groups of the less welloff population, it is desirable to keep the income at the same level and load the entire severity of the crisis on the remaining two groups of the richest people, fairly distributing the loss of income in accordance with the progressive taxation scale.

As we have already said, the two groups of the population with the highest incomes account for about $70 \%$ of the total cash income of the population. The hypothetical reduction of the total income by one third will make the wealthy people of these groups almost twice as poor. How vulnerable are these two groups to such a loss of income?

According to the Federal State Statistics Service, households spend on the purchase of nonfood products (cars, yachts, other home appliances, real estate, etc.) in the fifth highest-income group of the population, $40.8 \%$ of their income, and in the previous fourth group, $33.3 \%$ of income. The acquisition of these goods with the properties of deferred demand, as well as the repair and reconstruction of housing, foreign tourism, it is desirable to move beyond the corona crisis. As for food, the hypothetical progressive scale of taxation will not affect them. Therefore, a more even distribution of income due to the progressive scale of taxation, even in such a rigid hypothetical version as the one given above, does not pose a serious threat to the middle class. Not to mention the families of \$ 152 millionaires.

Depending on the situation, two models of anticrisis social support of the population are possible: 1) maintaining the level of minimum incomes (salaries, pensions, benefits) due to their indexation and insurance; 2) targeted social assistance to those in need. At the same time, social assistance can be provided in the form of unemployment benefits, support for large families, subsidies to enterprises for the payment of 
wages, etc. For example, A. Kudrin proposed to increase the minimum wage and unemployment benefits by one year, to provide subsidies to businesses for the payment of wages, using the National Welfare Fund and financial markets [5].

In addition to cash payments, assistance may come to those in need in kind: in the form of free meals, coupons for free food, medical care for the elderly, care for minors, etc.

The creation of a second economic structure for the accelerated development of SMEs opens up wide opportunities for self-realization and self-protection of the population from the impending crisis. At the same time, public opinion should be prepared for upcoming economic difficulties, for inevitable moderation in consumption and demands.

Conclusions. So, in anticipation of a possible economic crisis, two types of proactive anticrisis measures are considered.

Economic measures. Russia can oppose the possible reduction in economic activity under the influence of global market downturns, oil demand and prices, sanctions and a pandemic by the release of entrepreneurial initiatives by the population, local and regional authorities aimed at accelerating the growth of the supply of domestic consumer goods, domestic tourism services, production of aggregates, units and parts, components for cars, after-sales service of foreignmade aircraft and many other domestic goods and services, deputy importing. This "virgin land" of domestic business can be raised under the condition of a deep institutional reform aimed at creating a special economic structure for the development of SMEs.

Social measures. For the social protection of the population from the effects of the crisis, a progressive taxation scale widely known in world practice for highincome groups can be used. Calculations show that the correct increase in taxes on high incomes of the population will create pent-up demand for durable goods, but at the same time it will reduce the negative impact of the crisis on the least protected segments of the population. Rational redistribution of income in favor of the poor should not radically reduce the standard of living of the middle class. The redistribution of part of the income of the rich in favor of the low-income and poor as an anticrisis measure does not bear additional burden on the budget, does not require an increase in the money supply, and is not accompanied by an increase in inflation. Ultimately, it can serve to strengthen the public sector.

The social norm of the upcoming life of all segments of the population of Russia should be moderation in consumer demands and ambitions.

\section{CONFLICT OF INTEREST}

The authors declare that they have no conflicts of interest.

\section{REFERENCES}

1. V. K. Fal'tsman, Problems in Russia's Economy until 2050 (MAKS Press, Moscow, 2020) [in Russian].

2. V. K. Fal'tsman, "Problems of forecasting in small and medium business," Stud. Russ. Econ. Dev. 30, 10-14 (2019).

3. A. G. Aganbegyan, On Priorities of Social Policy (Delo, Moscow, 2018) [in Russian].

4. Economics according to Academician Ivanter, Ed. by B. N. Porfiryev, M. N. Uzyakov, A. A. Shirov, A. E. Ivanter, and I. V. Zubkov (Nauka, Moscow, 2020) [in Russian].

5. Vedomosti, Apr. 13 (2020). 